\title{
Analysis of the Ways of Comprehensive Learning in Chinese Teaching in Primary Schools
}

\section{Rongfen Li}

Teaching and Research Laboratory of Wudi County, Wudi, Shandong Province, China

ABSTRACT. In order to improve the practicality and comprehensiveness of the teaching of Chinese subjects, the new concept of "comprehensive learning" was put forward in the eighth curriculum reform. In the process of Chinese teaching, students' interest is mainly promoted. Through comprehensive learning activities, the primary school students' innovative spirit and teamwork ability are cultivated to further improve the teaching situation of primary school Chinese. This paper probes into the key points of comprehensive learning in primary school Chinese teaching and the ways of comprehensive learning in primary school Chinese teaching to achieve effective guidance for primary school students.

KEYWORDS : Primary School Chinese Teaching; Comprehensive Learning; Pathway Analysis

\section{Introduction}

According to the "Compulsory Education Chinese Curriculum Standards", regular comprehensive learning activities will be carried out to actively cultivate the creative consciousness of primary school students, and give full play to the comprehensive and practical teaching of Chinese subjects. Actively implement quality education, accelerate the reform of new curriculum, promote the interactive and open teaching process, and effectively enhance the practical value of comprehensive learning [1]. Understand the basic characteristics of comprehensive learning: cooperation, individualization, empiricism, comprehensiveness, and life, play the guiding role of teaching materials, give students effective education, help students improve their ability to use Chinese language, and adopt comprehensive learning. The method promotes the effective development of students' self-learning ability. 


\section{The focus of comprehensive learning in Chinese teaching in primary schools}

Make full use of text resources, flexibly use the content of teaching materials, plan comprehensive learning activities, strengthen the use of textbooks, and improve the utilization of text resources. Effective use of unit lead words, improve the effectiveness of primary school Chinese teaching, guide students to actively understand the characters in the text, movements and other knowledge, and timely grasp the character information. Using reading, close the distance between students and the characters in the text, promote students to be immersed in the good quality of the characters in time, and closely extend the teaching content around the teaching theme [2]. According to the content of the textbook and the characteristics of the subject, improve the artistic charm of the subject content, extend the classroom content to the extracurricular time, cultivate students' ability to use the language, conduct effective teaching material information mining, effectively carry out comprehensive learning, and create a learning exchange station for students. Public platforms such as extracurricular bookstores use network technology to collect information and improve the precipitation of teaching information.

\section{The analysis of the ways to carry out comprehensive learning in Chinese teaching in primary schools}

\subsection{Play the guiding role of comprehensive learning}

Conduct comprehensive learning activities to develop students' ability to master and use subject information. Under the development of information technology, use comprehensive learning to help students develop new learning goals in a timely manner, and use the Internet and multimedia to promote students' rapid grasp of subject information. Effectively processing the corresponding information and improving the ability to use the language helps to cultivate students' innovative consciousness and divergent students' thinking. In the process of comprehensive learning, the students' self-discipline and self-control level are greatly improved. With new teaching methods, we can solve the difficulties in students' learning in a timely manner [3].

\subsection{The main method of conducting comprehensive learning and teaching activities}

\subsubsection{Course content design}

\subsubsection{Synthesis of knowledge of the Chinese language system}

Integrate teaching objectives, teaching concepts and teaching methods. For example, actively reflect the value of teaching objectives and improve the knowledge ability of teaching objectives. Improve the understanding of subject textbooks, guide students to correct view of subject teaching, not excessive pursue 
the systematic and comprehensive goal of Chinese teaching, so as to improve the teaching objectives to help students clear their thinking and develop students' listening and speaking skills. Strengthen students' understanding and mastery of textbooks, form a perfect teaching goal system in time, and carry out effective curriculum content design to help students improve their understanding ability [4]. Combine teaching objectives, teaching concepts and teaching methods, improve the comprehensiveness of subject teaching, and carry out targeted comprehensive learning activities according to the psychological and cognitive level of primary school students, so as to better exercise students' oral expression ability.

\subsubsection{The integration of Chinese and other disciplines}

Focus on the integration of knowledge in various disciplines, guide students to get close to nature, enter nature, and consciously participate in environmental protection work, so as to promote students to observe life carefully, and use their own perceptions to deeply realize the beauty of nature. In the exchange guidance, combine the scientific literacy and humanistic literacy training, and actively undertake the important mission of promoting students' all-round development. At this stage, teachers should recognize that the Chinese language subject is not a separate subject. Thus, in order to improve students' academic performance, it is necessary to combine language subjects with ideological and moral, social studies, etc. The integration of knowledge in various disciplines, such as the combination of natural science and language, which can enable students to integrate and observe carefully in life, and develop good habits of recording at any time [5]. In Chinese learning, reading books, poems, and Tang-Song Poetry can accumulate reading quantities and cultivate the humanistic spirit of students. In reading, students can enrich their amount of information. Meanwhile, the combination of literature and audiovisual art can effectively stimulate students' hearing and vision, then students' comprehensive ability could be greatly improved in this context of mutual complementation and mutual learning. For example, in the elementary school classroom, The stillness of the night and Memories of The South, which students read carefully, cannot help immersing themselves in poetic Illusion, so that the essence of Chinese ancient poetry can be better presented, and the teaching content of Chinese language can be enriched.

\subsubsection{The combination of language subjects and network resources}

In Chinese teaching, the combination of subject content and network resources forms a curriculum-based Chinese language teaching system, which makes the original abstract teaching content more vivid. For example, in the teaching of situational dialogue, the means to help students understand is that teachers play related videos by multimedia to promote the dynamic display of the situational dialogue. Moreover, teachers can make use of network technology to display subject content, and fully use multimedia to explain the knowledge related ancient poetry to students, such as the author's life, story introduction, works analysis, and background of the times, in order to improve students' understanding of ancient poetry. 


\subsection{Curriculum resource development}

The Chinese subject has a wide range of aspects. In order to enhance students' language literacy, teachers can use the Internet to collect more teaching materials in the classroom and use network materials to link the various knowledge points of the discipline, and conduct timely integration analysis to improve the Chinese curriculum materials, expand the students' thinking.

Using family resources to exploit community resources. Family life has plenty of curriculum resources and daily conversations and communication among family members involve customs, geography and knowledge, which are valuable curriculum resources. (2) Carry out comprehensive learning practice of "sharing hometown cuisine", from which parents and children are closer together and use family resources to carry out comprehensive learning. (3) Improve the participation of primary school students, encouraging students to enter the community, observing life learning more about current social events, building an open and comprehensive Chinese language teaching environment, and organizing survey forms to expand curriculum resources to the outside of the school.

\subsection{Strengthen comprehensive learning practice}

Using the childlike innocence of the primary school students and the pupils' thinking is influenced by rich imagination, and students' minds are washed with vivid language. (1) Defining the goal of comprehensive practical teaching, focusing on creating fairy tales, cultivating the imagination of primary school students, effectively inspiring students, and promoting students to learn Chinese in their lives [6]. (2) Teachers and students use the Internet, multimedia and other means to collect texts related to fairy tales, improving students' information processing capabilities. (3) Group students. Each group composes a fable story or fairy tale and performs in the group. The team members evaluate it and the group leader tells each person's mistakes in language, expression and movement, which is good for improving students' performance ability. (4) The teacher checks at any time, designating group performs on the stage. One person reads aloud and other members perform role-playing, enhancing the students' sentiments. The students should perform affectionately, play their respective roles seriously and complete the learning task of story performance together.

\section{Conclusion}

In the language teaching of primary schools, teachers should clearly define he key points of comprehensive learning in time, understand the cognitive rules of students, and organize comprehensive learning activities according to the needs of students. The language subject should be combined with other disciplines, social disciplines and network resources. Using network materials to link the various knowledge points of the discipline. The combination of natural science and language makes students integrated, and the combination of language subjects and network 
resources makes the original abstract teaching content more vivid and specific. Encourage students to enter the community, observe life, use family resources, and expand curriculum resources in time to form a disciplined education system that increases student engagement.

\section{References}

[1] Zhang Baoyuan (2016). On the "Three Steps" of Comprehensive Chinese Learning in Primary Schools. Education Review (The second half of the month), Vol.5, No.10, 23-23.

[2] Liu Lifeng, Xu Hongmei(2013). Several experiences in carrying out comprehensive learning activities in primary schools. Ningxia Education Research, Vol.3, 46-47.

[3] Wang Qiaoting (2015). Focus on strategy to make comprehensive learning in primary school more attractive. Education and Teaching Forum, Vol.7, 97-98.

[4] Cao Guangquan. Research on the Teaching Strategies of Comprehensive Chinese Learning in Rural Primary Schools. Chinese Journal of Off-campus Education, (7): 155-155.

[5] Jiang Huiqin (2015). The Status and Reflections on the Implementation of Comprehensive Learning in Primary Schools__ Taking the Actual Situation of a Primary School as an Example. Primary School Chinese Teachers, Vol.12, 24-24.

[6] Yan Zhaohua(2016). Research on Comprehensive Chinese Learning in Primary School under the New Curriculum Concept. Journal of Yanbian Education College, Vol.30, No. 4, 118-120. 